\title{
Quantitative infrared thermography in fire tests
}

\author{
by $\mathrm{H}$. Heinrich and K.-H. Dahlem
}

Bauphysik - Technische Gebäudeausrüstung - Baulicher Brandschutz, University of Kaiserslautern D 67653 Kaiserslautern, Germany

\begin{abstract}
The classification of fire resistant occurs with the aid of the results of fire tests. The criteria for the classification are determined in european standards. The use of infrared thermography not only for qualitative observation but also for quantitative measurement during fire tests of glasses and glazings makes it possible to check the demands of national or international standards as ISO 3009 and forthcoming EN 1364 more exactly.
\end{abstract}

\section{Introduction}

In Germany for example more than 500 people are killed every year by fire and in addition the fire damages cost the national economy about 5 billion Deutsche Mark [1]. Various efforts are to be done to reduce this threat of human life and the loss of property. The possibilities and capabilities for fire fighting and in addition the fire protection in buildings have to be improved.

Infrared radiation is a valuable tool to be used for these purposes.

\section{Detecting of fire and fire fighting with thermography}

In Germany, already during World War II, infrared devices have been developed not only for military purposes but also for early detecting of area fires up to a distance of one hundred kilometers [2]. This technology was later on perfected. In 1994 infrared thermography cameras installed on towers were used for example in France to set up an early warning system for forest fire in the area of Bordeaux [3].

In the Eighties hand held infrared thermography cameras were introduced in fire departments to enable the firemen to act in areas filled with smoke [4]. Localization and rescue of wounded or unconscious people was drastically improved by this technique.

In modern stationary fire fighting systems, for example in industrial plants, carbon dioxide is used as an extinguishing medium. Carbon dioxide is stored in metal bottles which are linked together with a piping system. In a regular manner these bottles have to be checked if they are still correctly filled. If the bottles are heated slightly with a hot air pistol, a thermal contrast is created between the liquid level and the gas in the bottle. That level can be seen with a thermocamera and the correct height of liquid in the bottle can be detected [5].

\section{Fire protection}

Buildings have to be designed and constructed in such a way that in the case of a fire they provide optimal safety for people and property. Classic building structures consisting of concrete or bricks are normally not critical in their resistance to fire. But in modern buildings more and more translucent components are installed. These components must show appropriate fire protective properties due to national or international standards. New developed components as glazings, windows or doors must be therefore checked for their fire behaviour in fire tests. 


\section{Fire tests}

\subsection{Fire tests and thermal radiation}

In fire tests, components to be tested as glazings are installed in front of an oven according to [6] (Fig.1) and exposed to a predefined fire action. The temperature time-curve (standardized) is given by the international standard [6] and can be described:

$$
T-T_{o}=345 \cdot \lg (8 \cdot t+1)
$$

$T$ - temperature of the oven in $\mathrm{C}^{\circ}$

$T_{0}$ - temperature of tested element at the begining of the fire test in $\mathrm{C}^{\circ}$.

$t$ - time after begining of the fire test in min

To pass the test, different conditions have to be fulfilled [7] as:

$E$ - criterion $E$,integrity" according to [8] no passing of flames and smoke through glazing

$I$. - criterion $I$, insulation" according to [8] the temperature rise of the exterior surface of the glass must not exceed $140 \mathrm{~K}$ (mean value), respectively $180 \mathrm{~K}$ (maximum value)

$W$ - criterion $W$ according to [8]

maximum value of irradiance $E$ at a given distance must not be exceeded

The last condition describes that people are able to escape by passing the glazed partition in a certain period of time:

After 5 seconds of exposure the irradiance $E$ must not exceed $9600 \mathrm{~W} / \mathrm{m}^{2}$ and after 60 seconds of exposure it must not exceed $3350 \mathrm{~W} / \mathrm{m}^{2}$. These two conditions can be combined to a hyperbola $[9,10]$ :

$$
E=\frac{19,07}{t^{0,424}}
$$

$E$ - irradiance in $\mathrm{kW}$

$t$ - time of exposure in s

That curve (Fig.2) describes the maximum endurable irradiance $E$ on a human body.

\subsection{Conventional methods}

To check the conditions in 4.1 , conventially the temperatures at the surface of the glazing are measured with some thermocouples (Fig.1). The problem is, that it is difficult to verify how representative these measurements are and consequently it is not clear and sure if the conditions are really fulfilled.

\subsection{Fire tests with thermography}

It is therefore convenient to use an infrared thermography camera system to control the whole surface of the element during the fire test. Fig. 3 and Fig.4 show two thermograms taken at different times after starting the fire test. A time dependent analysis of the thermograms shows average, minimum and maximum temperature. It has to be taken into consideration, that the emissivity of glass and the other materials used may depend on temperature. So condition $I$ in 4.1 can be easily checked.

Fig. 5 shows the time-dependent curve of the surface temperature of the glass in a fire test. It is to be seen, that there are great differences between the minimum and the maximum temperatures after 30 minutes. The measurements recorded with contact temperature sensors at different prescribed points that is shown in Fig. 1 could not provide the maximum temperature of the glass because the maxima are lying in the border zone. 
To determine the irradiance $E$ on a hypothetic human body, first of all the radiant exitance $M$ of the surface of the glazed element has to be calculated using the temperatures given by the thermograms:

$$
M=\sigma \cdot \varepsilon \cdot\left(T^{4}-T_{E}^{4}\right)
$$

$M$ - radiant existance in $\mathrm{W} / \mathrm{m}^{2}$

$\sigma$ - Stefan-Boltzmann constant $=5.7 \cdot 10^{-8} \mathrm{~W} /\left(\mathrm{m}^{2} \mathrm{~K}^{4}\right)$

$\varepsilon$ - emissivity of the tested element

$T$ - surface temperature of the tested element in $\mathrm{K}$

$T_{E}$ - environment temperature in $\mathrm{K}$

The relation between $M$ and $E$ is given by a geometrical factor $\varphi$. That factor depends upon the size of the glazing, i.e. size of the emitting surface, the distance to the assumed human body, its size and the angles [11].

$$
E=M \cdot \varphi
$$

In a realistic example, 30 minutes after the begining of the fire test, $M$ can be determined to $M=785 \mathrm{~W} / \mathrm{m}^{2}$. Due to the given geometrical situation in this case $\varphi$ is calculated to:

$$
\varphi=0,66
$$

So the irradiance $E$ received by a human body is calculated to:

$$
E=518 \mathrm{~W} / \mathrm{m}^{2}
$$
met.

Compared with the curve in equation (2) it is obvious that the required conditions are

\section{Conclusion}

In conclusion, infrared thermography is shown to be a useful aid in fire tests of glazing. The demands of national or international standards which are required to fire resitant glazing can be checked for the whole surface in contrast to the measurement with contact temperature sensors at several points. So it is possible to find very simply the maximum and the mean temperature of the object in the fire test by infrared themography.

\section{Acknowledgements}

The authors thanks Prof. W. Becker, University of Kaiserslautern, Germany, for his very helpful suggestions and references to the actual standards and Dipl.-Ing. D. Lorenz for his contributions to the analysis of the experimental results.

\section{REFERENCES}

[1] FRIEDL (W. J.) Ökologische und ökonomische Bedeutung des Brand- und Explosionsschutzes, Kohlhammer-Verlag, Stuttgart 1998.

[2] ISRAEL (H.) Messen und Orten mit Infrarot, Franzis-Verlag, München 1988.

[3] V. (Ch.) Infrarotkameras überwachen den Wald, VDI-Nachrichten, 09.11.1994.

[4] N.N. Wärmebildkamera zur Brandbekämpfung, elektrotechnik, 64, H.7, April 1982.

[5] HOVLAND (J.) Thermografic control of $\mathrm{CO}_{2}$ bottles in stationary fire fighting equipment, International Thermography Association Congress '98, Skien, Norway 1998.

[6] ISO 834 Fire-resistance tests; Elements of building construction [Feuerbeständigkeitsprüfungen; Baukonstruktionsteile], first edition 1998.

[7] see also forthcoming EN 1363-1 (1999).

[8] ISO 3009 Fire-resistance tests; Glazed elements [Feuerbeständigkeitsprüfungen; verglaste Bauteile], first edition 1976-10. 
[9] see also forthcoming EN 1364 serie (1999).

[10] EUROPEAN COMMISION - Interpretative Document Fire Safety in Buildings, 1994.

[11] LORENZ (D.) - Multifunktionale Brandschutzverglasung als Festverglasung und/oder als öffenbares System, Diplomarbeit, Universität Kaiserslautern, Februar 1998.

[12] VORTMEYER (D.) Einstrahlzahlen, VDI-Wärmeatlas, Abschnitt Kb, VDI-Verlag, Düsseldorf 1988.

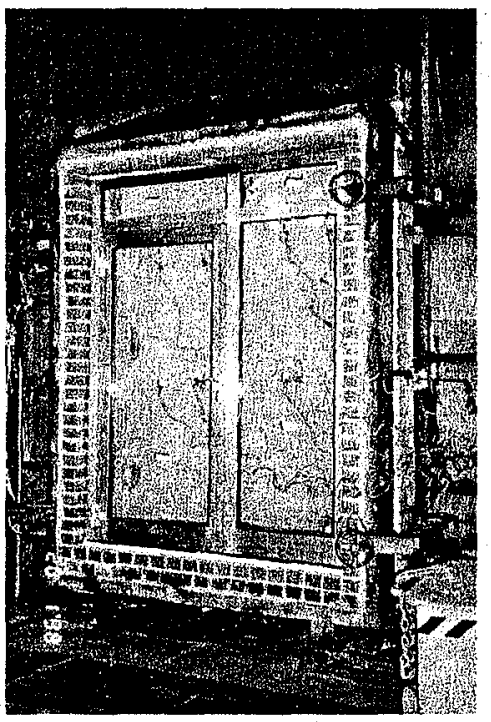

Fig. 1.Glazing element mounted in front of oven for fire tests

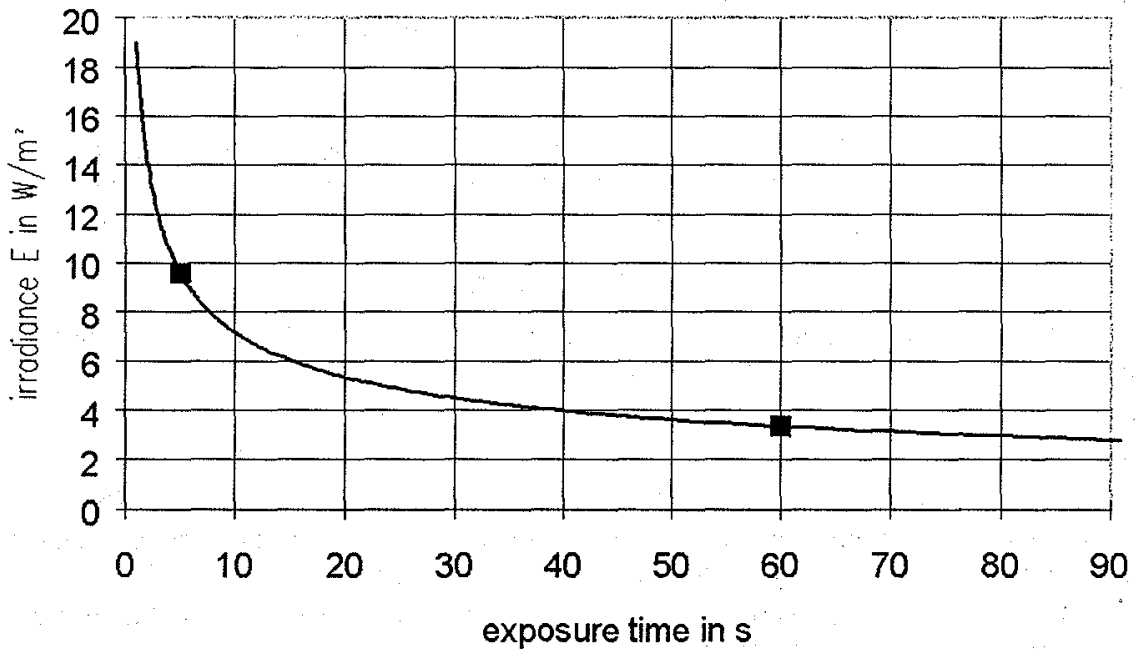

Fig. 2. Maximum endurable irradiance $E$ on a human body 


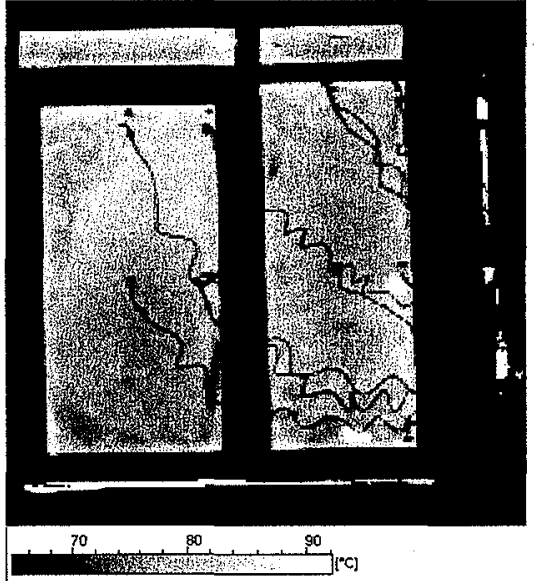

Fig. 3. Thermogram of a glazed element 648 seconds after the begin of the fire test

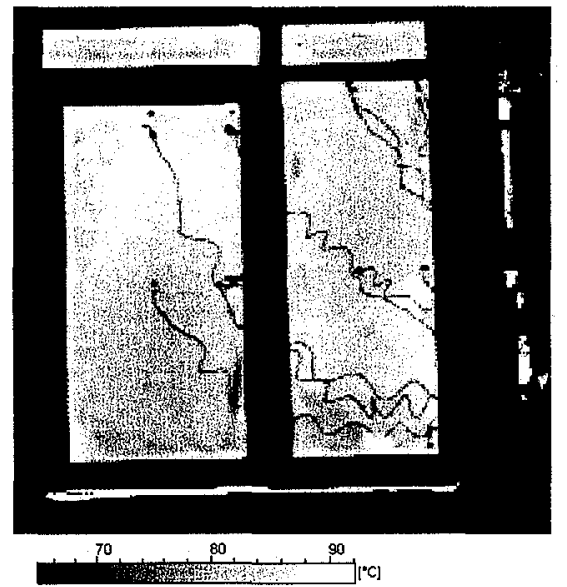

Fig. 4. Thermogram of a glazed element 698 seconds after the begin of the fire test

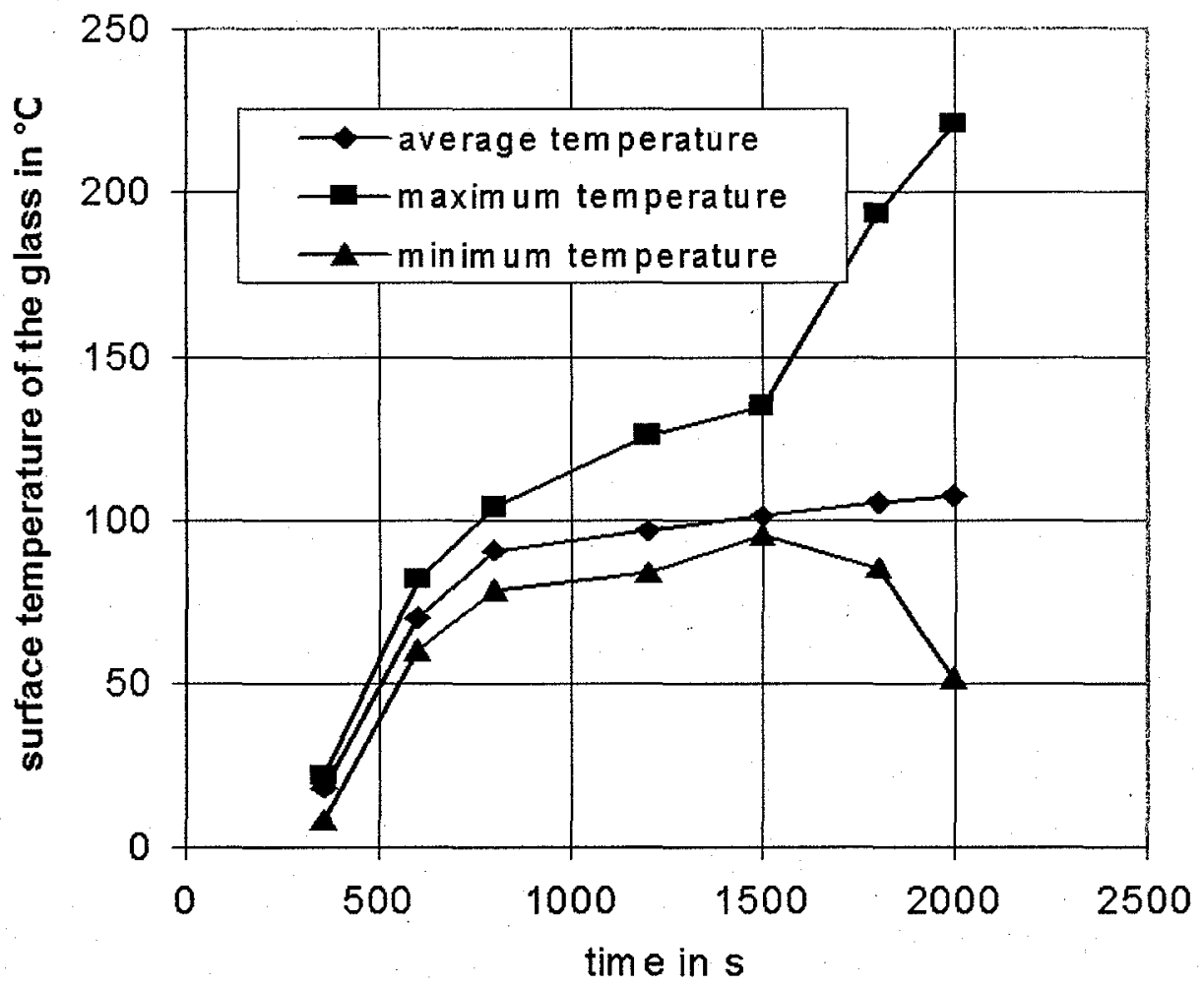

Fig. 5. Surface temperature of glass during a fire test 